\title{
The C-E Translation of Guangxi Ethnomedicine Works from the Perspective of Eco-translatology: Take The Selected Edition of Zhuang Medicine as an Example
}

\author{
CHEN Dongyan \& TANG Guoping \\ College of International Studies, Beibu Gulf University, China \\ Received: August 29, 2021 \\ Accepted: September 26, 2021 \\ Published: November 30, 2021
}

To cite this article: CHEN Dongyan \& TANG Guoping. (2021). The C-E Translation of Guangxi Ethnomedicine Works from the Perspective of Eco-translatology: Take The Selected Edition of Zhuang Medicine as an Example. Asia-Pacific Journal of Humanities and Social Sciences, 01:3, 190-195, DOI: 10.53789/j.1653-0465.2021.0103.021.p

To link to this article: https://doi.org/10.53789/ j.1653-0465.2021.0103.021.p

The research entitled "Translation and Publicity Strategies of Guangxi Ethnomedicine" is supported by Guangxi Education Department with No.2021ky0411.

\begin{abstract}
Guangxi has many works on ethnomedicine, among which The Selected Edition of Zhuang Medicine is professional and authoritative. It comprehensively collects and creatively applies Zhuang Medicine resources and has important value for international publicity in severe COVID-19. Under the guidance of Eco-translatology Theory, taking the English translation of Selaginella doederleinii Hieron in the book as an example, this paper explores the English translation strategies of Guangxi ethnomedicine, aiming to provide some of the English translation strategies references for the translation of Guangxi and even China's ethnomedicine.
\end{abstract}

Keywords: Guangxi ethnomedicine; Eco-translatology; Selected Edition of Zhuang Medicine

Notes on the contributors: CHEN Dongyan holds a master's degree in English Interpretation, and she is a teacher at Beibu Gulf University. Her academic interest lies in cognitive linguistics, translation theory and practice. TANG Guoping holds a master's degree in Linguistics, and he is currently a professor at Beibu Gulf University. His academic interest lies in translation theory and practice.

\section{生態翻譯學視域下廣西民族藥著作英譯研究 以《壯藥選編》中“深綠卷柏”簡介的英譯爲例}

\author{
陳冬雁 唐國平 \\ 北部灣大學國際教育與外國語學院
}

摘 要: 廣西民族藥著作豐富, 其中《壯藥選編》對壯藥資源進行了全面的搜集整理和創新應用, 専業權威, 在疫情 嚴峻的形勢下具有重要的外宣推廣價值。在生態翻譯學的指導下, 以《壯藥選編》中藥材 “深綠卷柏” 簡介的英譯 
営例,探究廣西民族藥英譯在語言維、文化維和交際維的適應性轉換,從而虎廣西乃至中國民族藥著作的英譯提供 借監,提高中國民族藥文化在海外的接受度和認可度。

關鍵詞: 廣西民族藥; 生態翻譯學; 《壯藥選編》

基金項目:廣西高校中青年教師科研基礎能力提升項目(立項編號 2021KY0411)

\section{引言}

廣西是中醫藥民族醫藥大省, 中草藥物種達 4600 多種,數量在全國名列第二(1)。在新冠疫情防控期間, 廣西的《壯醫防治方案》、瑤醫 “組合拳療法” 等在防治新冠肺炎中療效顯著。因此, 加強廣西民族藥的翻譯 研究對全球新冠疫情的防控有現實意義,對促進世界醫療事業的國際合作也有重要作用。《壯藥選編》 ${ }^{2}$ 是 對壯藥資源全面系統的整理, 也是貫徹國家支持少數民族醫藥發展的重要成果, 其英譯研究有助于完善廣 西民族藥的外宣翻譯體系, 提高其外宣水平,進一步提升廣西乃至中國民族藥文化的國際影響力。此著作 中每一種壯藥的簡介都遵循統一的文字編排格式,所以從中選出了最具代表性的壯藥“深綠卷柏” 來深人研 究其英譯策略,其它壯藥簡介的英譯都可以借鑒。國内學者對民族藥英譯的研究大多從語言學的視角出 發, 本文擬以生態翻譯學理論爲指導, 以“三維適應性選擇轉換” 爲切人點, 對《壯藥選編》中 “深綠卷柏”簡 介的英譯進行研究, 力求産出高質量的譯文, 從而提升廣西民族藥的英譯質量, 向外傳播優秀的民族醫藥 文化。

\section{一、生態翻譯學}

\section{（一）生態翻譯學要點概述}

生態翻譯學是胡庚申教授在“翻譯適應選擇論” ${ }^{3}$ 基礎上提出的全新翻譯理論, 認爲“翻譯即生態平衡、 即文本移植、即適應選擇” “譯者是翻譯的主體, 首先要適應翻譯生態環境, 然後對譯文進行優化選擇, 在 語言維、文化維、交際維進行適應性轉換,從而實現原文和譯文的生態平衡 ${ }^{(5)}$ 。它明確指出了自然生態和翻 譯生態之間的高度融合, 側重生態的整體性與和諧性, 避免了傳統翻譯論的片面性和單一性,相較于目的 論、語言學、文化學等翻譯指導路徑來說其理論優勢和方法論的包容性更大, 這是其它翻譯指導路徑難于比 擬的。

\section{（二）生態翻譯學與廣西民族藥著作英譯}

民族藥著作英譯本身就是一個葸含著“語言、文化和交際” 的生態整體, 因此以強調整體性與和諧性的 生態翻譯學理論來指導更爲貼合。在這一過程中,譯者首先要處理多種語言的差異 (壯語及其它-漢語-英 語), 包含詞彙選擇、語言形式和結構等, 其次是跨越民族藥學和西藥學的文化差異, 使受衆能夠接受源語文 化的部分 (壯瑤侗民族文化等), 最終通過准確傳達源語的交際意圖來實現民族藥文化的國際傳播, 這與生 態翻譯學指導下的 “三維” 翻譯方法是一致的。基于此,生態翻譯學理論非常適用于廣西民族藥著作英譯, 爲其提供了新的翻譯理論、原則和方法。

\section{二、廣西民族藥著作英譯的“三維”轉換}

生態翻譯學認爲翻譯過程是譯者“適應”與“選擇”交替循環的過程,翻譯原則是多維度的優化選擇與適 
應, 翻譯方法是 “三維” (語言維、交際維、文化維) 轉換, 從而整合出適應度最高的譯文 ${ }^{\circledR}$ 。以這一理論爲指 導, 筆者以《壯藥選編》中 “深綠卷柏” 簡介的英譯爲例, 通過 “三維” 轉換來探討廣西民族藥著作的英譯策 略。在語言維方面,譯者主要采取句型和語序調整等翻譯技巧確保原文的語言形式和意義在譯人語中得以 重現; 在文化維方面,采用音譯加注的方式傳遞原文中的文化信息; 在交際維方面,通過術語統一、意譯和增 譯等翻譯技巧來實現原文的交際意圖。

\section{（一）語言維一語言層面的通順}

語言維的轉換即語言形式的適應選擇轉換。譯者要准確把握原文的語言形式和風格,通過適應轉換, 使譯文符合譯語規範和表達習慣, 以求能爲讀者所接受, 尤其是醫學讀者, 其認可和接受直接決定了對某種 民族藥的信任與應用。因此,在廣西民族藥的英譯中,需要通過語序、語義、句式調整等整合出符合英語讀 者期待的譯文。

例 1 : 主蕉直立,常在下部分枝處生出不定根。主荎自下部開始羽狀分枝: 側枝 3-6 對,2-3 回羽狀分 枝,分枝稀疏,無毛, 背腹壓扁。

譯文:The main stem, which is upright and often produces adventitious roots at the lower branches, starts with pinnate branches from the lower part : 3-6 pairs of lateral branches and 2-3 pinnate branches which is sparse and glabrous with flat back and abdomen. (筆者譯)

此例中的兩句中文的主語皆爲“主莖”, 漢語傾向于使用短句且多重複, 英語則更傾向于使用邏輯緊密 的長句且多變化 ${ }^{7}$, 所以此處譯文將兩句同一主語的中文短句轉換成了邏輯緊密的長句。此外, 漢語強調意 合,較少使用連接詞,句子成分是通過邏輯意義連接起來的,而英語重形合,一般會使用邏輯緊密的連接詞 來連接不同的成分。例如此例中描繪“羽狀分支” 的是平行結構的短句, 即其特點是稀疏、無毛且背腹壓扁, 譯文根據中英差異補充了 “which”、“and”、“with”等連接詞。通過以上調整, 原文轉換成了一個邏輯層次分 明、表意清晰的主從結構,符合英語讀者所期待的文本形式,實現了語言維的適應選擇轉換。

例 2 :孢子葉穗緊密,四棱柱形, 單個或成對生于小枝末端; 孢子葉圓形至卵狀三角形,邊緣有細齒; 孢子 葉穗上大、小孢子葉相間排列,或大孢子葉分布于基部的下側。

譯文:The sporophyll spike is compact and quadrangular, growing single or paired at the end of branchlets, with large or small sporophyll arranged alternately on it or large sporophyll under its base. The sporophyll is round to ovate triangular, with fine serrations at the edge. (筆者 譯)

此例中描述順序爲狍子葉穗-孢子葉-孢子葉穗-孢子葉, 沒有按同類内容的順序擺放。那是因爲漢語 重意合, 即使語序靈活和邏輯不密也不影響理解, 英語則不然,一個句子的主要成分通常緊密地排列在一 起,並在前面或結尾放置各種修飾語 ${ }^{8}$, 而且必須使用邏輯連接詞來銜接所有成分並顯示成分之間的邏輯關 系。所以譯文對語序進行了調整並添加了“and”、“with”等連接詞，把孢子葉穗和孢子葉的相關内容分別歸 到一個句群並形成邏輯連貫、表意清晰的長句,符合英語讀者所期待的文本形式,實現了語言維的適應選擇 轉換。

\section{（二）文化維一文化内涵的傳達}

文化維的轉換,即“注重文化內涵的傳達” (9 要求譯者關注思想傳遞和文化移植,避免文化誤讀和語用 失誤。受中國哲學和文化的影響, 民族醫藥辨證施治常采用 “取象比類” 的方式對病因病症、治療用藥等加 以描述和概括, 具有整體性、隱喻性及模糊性等特點 ${ }^{\circledR}$ 。因此,在民族藥的英譯中, 譯者應充分考慮原文所蘊 含的民族文化元素和特色, 既保證傳達文化內涵, 又確保讀者的接受度。 
例 3: 功用: 調龍路、火路。用於發旺, 奔唉, 貨煙媽, 黃標, 唄嘻, 楞澀, 參福相。

譯文:Functions: Tiao Longlu \& Huolu (promoting circulation of channel). It is also used for Fawang (arthralgia disease), Benai (cough), Huo Yanma ( sore throat), Huang Biao (jaundice), Baixi (mastitis), Lengse ( rhinitis) and Shen Dangxiang (burn and scald). (筆者譯)

此例中原文出現了很多壯醫藥的文化負載詞,例如龍路和火路是壯醫采用 “取象比類” 的方式總結出來 的壯醫藥隱喻術語,其余的是病症名稱的壯語讀音,用發音近似的漢字記述,即“音譯病名” (1)。音譯病名藴 含著壯族文化特色和壯醫藥文化的精髓。爲最大限度地保留壯語的文化特色, 有效地傳播壯醫藥文化, 譯 者采用了音譯加注的方式, 既讓讀者在音譯中感受到壯醫藥發音的特色, 又可在注釋中理解這些文化負載 詞對應現代醫學的含義,實現了文化維的有效轉換。

\begin{tabular}{|c|c|c|c|}
\hline 壯醫名稱 & 形狀象似或發音近似 & 中醫名稱 & 西方現代醫學( 英譯) \\
\hline 龍路 & 貨煙媽 & \multirow{2}{*}{ 經絡 } & \multirow{2}{*}{ Longlu \& Huolu ( channel) } \\
\hline 火路 & 黄標 & & \\
\hline Fatvangh & 唄嘻 & 痹病 & Fawang (arthralgia disease) \\
\hline Baenzae & 楞澀 & 咳嗽 & Benai ( cough) \\
\hline Hozinmaz & 渗福相 & 咽痛 & Huo Yanma ( sore throat) \\
\hline Vuengzbiu & 貨煙媽 & 黄疸 & Huang Biao (jaundice) \\
\hline Baezcij & 黄標 & 乳腺炎 & Baixi (mastitis) \\
\hline Ndaengsaek & 唄嘻 & 鼻炎 & Lengse ( rhinitis) \\
\hline Coemhdangqsieng & 楞澀 & 燒洹傷 & Shen Dangxiang (burn and scald) \\
\hline
\end{tabular}

表 1 壯醫一中醫一西方現代醫學的文化維轉換

\section{(三) 交際維一交際意圖的達成}

交際維的轉換指“注重交際意圖的達成”, 通過交際維度的適應選擇轉換, 使譯語達成交際目的 ${ }^{12}$ 。由于 民族醫藥和西方現代醫藥往往在內容信息、寫作規範、風格體裁等方面差別很大, 翻譯中照搬原文内容和形 式通常會導致譯文模糊難懂,難以爲讀者所接受, 交際效果較差。所以,爲照顧交際維的有效轉換, 在廣西 民族藥英譯中譯者需打破原文內容和形式的束縛, 根據譯人語言和文化規範采取恰當的翻譯方法, 做出適 當的調整,使譯文在譯語環境中實現等同或接近原文的交際意圖。

例 4 : 附方: 小鉆，狗肝菜。

譯文:Attaching Formulas: Kadsura longipedunculata Finet et Gagnep, Dicliptera chinensis ( L. ) Juss. (筆者 譯）

此例中原文的“小鑽” 和“狗肝菜”均沒有國際統一通用譯文,如果用音譯、音譯加注或意譯均無法讓英 語讀者識別是哪一種藥材。于是譯者對這兩種藥材進行了考證, 發現“小鑽” 的別名 “南五味子” 和 “狗肝 菜” 的別名“四籽馬藍” 有國際統一通用譯文, 于是從達成交際意圖出發, 把這兩種藥材的譯文轉換成其別名 的譯文, 遵循國際英語同一性的翻譯標准 ${ }^{13}$, 實現了有效交際。

例 5 : 爛皮蛇、退雲草。

譯文:Zoster-treating Selaginella, Nebula-treating Selaginella.( 筆者 譯)

此例中原文的 “爛皮蛇” 是民族醫藥中一種帶狀疱疹的名稱, 這個別名是爲了凸顯這種藥草可以治療 “爛皮蛇”, 所以譯者采用意譯法, 譯爲 Zoster-treating Selaginella (治療帶狀疮疹的卷柏) ; 原文的“退雲草” 中 
的 “雲”指的是角膜雲鷖, “退雲” 是指其可以治療眼睛熱毒和炎症, 這個別名是爲了凸顯其功用, 所以譯者采 用意譯法, 譯成了 Nebula-treating Selaginella(治療角膜雲鷖的卷柏)。通過意譯法的處理, 民族藥特殊名稱 的深意有機地轉化爲譯語的表層結構, 再現了原語的蘊意, 真實傳達原語內涵 ${ }^{\circledR}$, 解決了民族藥漢英文本不 對等的問題,實現了有效交際。

\section{三、翻譯評估}

本文以問卷設計及分析來研究上述譯文在英語讀者中的接受程度,共成功回收所有發放的 20 份調查問 卷。問卷中設計了三個題目:第一個題目,筆者截取了“深綠卷柏”譯文的兩個小語段,以評分題的形式讓讀 者對語段的理解程度做一個基本的評價。第二個題目, 筆者通過整理《壯藥選編》中的 4 個圖片, 讓讀者將 語段和圖片做配對, 以此來檢驗受衆是否可從譯文識別 “深綠卷柏”。第三個題目則是多選題, 讓讀者根據 語段選出 “深綠卷柏” 的功用。此份問卷充分考慮英語讀者對此譯文的理解度、對這一民族藥的識別和功用 的認知,符合民族藥外宣的目的,所以設計較爲合理,有實際的參考應用價值, 可用于評估翻譯效度。

\begin{tabular}{|l|c|c|c|c|}
\hline \multicolumn{1}{|c|}{ 选项 } & 非常困惑 & 困惑 & 基本理解 & 完全理解 \\
\hline$[$ 形態特征]選段譯文 & 0 & 2 & 15 & 3 \\
\hline$[$ 壯監藥用]選段譯文 & 0 & 1 & 18 & 1 \\
\hline
\end{tabular}

\section{表 2 第一題評價題完成情況}

从各選項的选择人数来看, 仅有 3 个读者选择 “困惑” 選項, 可见问卷中有关的 “深绿卷柏” 选段的语料 是基本能够为英语读者理解的。从表 2 整体来看, 两个选段的理解率在 $75 \%$ 以上, 初步验证了翻译效度是 令人满意的。

\begin{tabular}{|c|c|c|c|c|}
\hline 选项 & 圆 1: 小鉆 & 圖 2:深綠卷柏 & 圖 3:狗肝菜 & 圖 4: 桃金娘 \\
\hline$[$ 形態特征]選段譯文 & 0 & 19 & 1 & 0 \\
\hline
\end{tabular}

\section{表 3 第二題圖片匹配題完成情況}

從選擇各圖的人數來看,僅有 1 個讀者選擇了錯誤圖片, 可見受衆可從譯文識別“深綠卷柏”。

\begin{tabular}{|c|c|c|c|c|c|c|c|}
\hline 题项 & A.t hroat & B. stomach & C. breast & D. nose & E. muscle & F. respiratory tract & G. skin \\
\hline [壯醫藥用]選段譯文 & 20 & 1 & 18 & 20 & 2 & 20 & 20 \\
\hline
\end{tabular}

表 4 第三題多選題完成情況

從各項的選擇人數來看,除了 3 位讀者選到了錯誤的功用, 其他讀者選擇正確率在 $90 \%$ 以上, 可見讀者 從譯文基本能正確認知其功用。

綜上所述, 譯文基本能夠爲英語讀者所理解和認知, 翻譯效度比較滿意, 但譯文還需打

磨使其更精准,因爲醫學方面容不得半點偏差。

\section{結語}

從以上的例證可以看出, 用生態翻譯學理論來指導廣西民族藥著作的英譯不僅豐富了生態翻譯學的内 
涵和外延, 也爲廣西乃至中國民族藥著作的英譯研究開拓了新思路。本文中所舉的例子, 分別從語言維、文 化維和交際維的單個層面進行, 是爲了更好地探討翻譯策略, 在實際英譯過程中應同時兼顧三個維度, 對整 個翻譯生態環境進行適應性選擇轉換, 以期達到最佳翻譯。生態翻譯學不管從理論還是實踐方面都能對民 族藥英譯起到一定的指導作用, 有助于譯者克服中英文語言和中西醫文化差異實現有效交際, 促進了今後 的民族醫藥英譯研究, 爲廣西乃至中國民族醫藥文化的外宣和交流貢獻了力量。

\section{注釋}

(1) 尤劍鹏: 《“互聯網+”背景下廣西壯釉醫藥創新發展初探》,《廣西中醫藥期刊》2017 年第 4 期, 頁 1-3

(2) 黄瑞松著, 《壯藥選编》, 廣西科學技術出版社 2015 年版, 頁 1-10。

(3)(9)12) 胡庚申著,《翻譯適應選擇論》, 湖北教育出版社 2004 年版, 頁 129-133。

(4) 王珊珊:《適應與選擇: 生態翻譯學視域下的中醫英譯》《《西部中醫藥期刊》2019年第 12 期, 頁 148-151。

(5) 胡庚申:《生態翻譯學: 生態理性特征及其對翻譯研究的啓示》,《中國外語》2011 年第 6 期, 頁 96-99, 109。

(6) 胡庚申:《生態翻暲學解讀》,《中國翻譯》2008 第 6 期, 頁 $11-15$ 。

(7)8 張丹:《《綿陽中醫簡史>漠英翻譯實踐報告》,《西南科技大學》2021 年第 6 期, 頁 13-17。

(10) 望麗影: 《中醫藥文化推廣困境: 中醫隱喻性語言的解讀與翻譯》,《锦州醫科大學學報 (社會科學版) 2021 第 4 期, 頁 103-106。

(11) 曾振東: 《壯醫常見病症名稱考釋》,《中國民族醫藥雜志》2014 年第 1 期, 頁 58-61。

(13) 周鋒: 《少數民族傅統醫藥翻譯策略研究》,《教育教學論壇》2019 年第 34 期, 頁 51-52。

(14) 朱建平: 《中醫病名英譯規範策略》,《中國科技衍語》2008 年第 2 期, 頁 18-24。 